\author{
В. А. Острога \\ Белорусский государственный университет
}

\title{
СЮЖЕТЫ ПО ИСТОРИИ РОССИИ В УЧЕБНЫХ ПРОГРАММАХ ПО РУССКОЙ ЛИТЕРАТУРЕ В СРЕДНИХ ШКОЛАХ РЕСПУБЛИКИ БЕЛАРУСЬ
}

\begin{abstract}
В статье на основе анализа учебников и учебных программ для 5-11 классов по «Русской литературе» для средних школ Республики Беларусь рассматриваются особенности отражения в них сюжетов по истории России. Наличие лучших образцов российской художественной литературы различных эпох в белорусской школьной программе позволяет учащемуся более глубоко познать российское прошлое, что в итоге содействует взаимопознанию и взаимодействию белорусской и российской культур. Делается вывод о значительном внимании разработчиков к наличию в учебных материалах российской исторической тематики. Однако в рамках дальнейшего развития белорусско-российского взаимодействия в образовательной сфере предлагается включить в учебной план средней школы Российской Федерации отдельную учебную дисциплину «Белорусская литература» либо включить темы по белорусской литературе в том же объеме учебных часов, как и в Республике Беларусь.
\end{abstract}

Ключевые слова: художественное произведение, русская литература, исторические сюжеты, история России, учебник, учебная программа, средняя школа, межкультурное взаимодействие.

Для цитирования: Острога В. А. Сюжеты по истории России в учебных программах по русской литературе в средних школах Республики Беларусь // Труды БГТУ. Сер. 6, История, философия. 2021. № 2 (251). С. 46-51.

\author{
V. A. Astroha \\ Belarusian State University
}

\section{SUBJECTS ON THE HISTORY OF RUSSIA IN THE CURRICULA OF RUSSIAN LITERATURE IN SECONDARY SCHOOLS OF THE REPUBLIC OF BELARUS}

The article analyzes textbooks and curricula for grades 5-11 on "Russian literature" for secondary schools of the Republic of Belarus and examines the peculiarities of reflecting subjects on the history of Russia in them. The presence of the best examples of Russian fiction of various eras in the Belarusian school curriculum allows the student to learn more deeply about the Russian past, which ultimately contributes to mutual understanding and interaction between the two Belarusian and Russian cultures. The conclusion is made about the considerable attention of developers to the presence of Russian historical topics in educational materials. However, as part of the further development of the Belarusian-Russian cooperation in the educational sphere, it is proposed to include a separate academic discipline "Belarusian Literature" in the curriculum of the secondary school of the Russian Federation or to include topics on Belarusian literature in the same amount of academic hours as in the Republic of Belarus.

Key words: fiction, Russian literature, historical subjects, history of Russia, textbook, curriculum, secondary school, intercultural interaction.

For citation: Astroha V. A. Subjects on the history of Russia in the curricula of Russian literature in secondary schools of the Republic of Belarus. Proceedings of BSTU, issue 6, History, Philosophy, 2021, no. 2 (251), pp. 46-51 (In Russian).

Введение. Познание исторического прошлого в школе, как известно, не ограничивается только уроками истории. Историческому образованию школьников различных классов содействует, в частности, и изучение литературы. Так, на занятиях по русской литературе, которую в белорусских школах проходят весь период школьного обучения, дети узнают много известных или малоизвестных дополнительных исторических фактов из прошлого России. Это дает возможность более ярко представить историю соседнего государства, позволяет с помощью образов художественной литературы различных эпох более глубоко познать российское минулое, что в итоге содействует взаимопознанию и взаимодействию двух культур, белорусской и российской.

В данном исследовании будут рассмотрены сюжеты по истории России в учебных программах по русской литературе в средних школах Республики Беларусь. В настоящее время это малоизученная и актуальная тема, рассматриваемая зачастую не на академическом, а на журналистском, публицистическом уровне. 
Основная часть. Говоря о современной ситуации в учебных программах по литературе в белорусских школах, необходимо сразу отметить, что там изучаются два полноценных и фактически равных по учебным часам предмета - «Белорусская литература» и «Русская литература». Вместе с тем в учебные программы дисциплины «Русская литература», помимо произведений, являющихся примерами литературного богатства России, внесены и произведения французской, британской, американской и литературы других стран. В этой связи учебный предмет, вероятно, мог бы называться «Зарубежная литература» или «Русская и зарубежная литература». Однако он именуется именно «Русская литература» и это оправдано, так как в ходе большинства уроков рассматриваются в основном произведения российских авторов, хотя в учебных программах имеется специальный раздел «Зарубежная литература».

Проанализируем отображение исторического прошлого России поклассно. Как отмечается в учебной программе по предмету «Русская литература» для V класса учреждений общего среднего образования с белорусским и русским языками обучения и воспитания Министерства образования Республики Беларусь: «целью изучения литературы является приобщение учащихся к искусству слова в контексте движения духовной и социально-исторической жизни народа и развитие на этой основе художественного мышления и эстетических чувств, творческих способностей, читательской и речевой культуры, формирование нравственно-эстетических ориентаций» $[1$, с. 1]. Среди изучаемых белорусскими пятиклассниками разделов «Русской литературы» есть раздел «Историческое прошлое в литературных произведениях», куда включены творения М. Ю. Лермонтова о Бородинской битве («Бородино»), И. С. Тургенева о крепостничестве («Муму»), Л. Н. Толстого о Кавказских войнах XIX в. («Кавказский пленник»), на взгляд авторов, главная мысль которых определяется словами пушкинского летописца из трагедии «Борис Годунов»: «Минувшее проходит предо мною...» [1, с. 3]. Хотелось бы обратить внимание на вопросы авторов учебника к ученику, которые требуют от него осознанного погружения в историю России. Наиболее показательно это в отношении к стихотворению М. Ю. Лермонтова. Так, у школьника просят рассмотреть репродукцию картины Ф. А. Рубо «Бородинская битва» и ответить на вопросы. Как художник передает напряженность боя? В каком месте сражения мог быть старый солдат-рассказчик? Какие детали Бородинского сражения нашли отражение на репродукциях картин А. С. Чагадаева и В. Г. Правдина? Какие строки стихотворения М. Ю. Лермонтова созвучны этим картинам? Также ученика просят нарисовать портрет старого или молодого солдата (словами, красками, карандашами); либо используя пластилин или плотную бумагу и краски, воссоздать фигурки солдат русской и французской армий; затем организовать выставку работ. Вопрос 8 просит выразительно прочитать строки, которые наиболее ярко передают патриотизм русских солдат, а девятый прочитать стихотворение М. Ю. Лермонтова «Два великана», посвященное Отечественной войне 1812 г., и подумать, кого подразумевает поэт под «русским витязем», а кого - под «двухнедельным удальцом» $[2$, c. 81$]$.

Как отмечают составители учебной программы по русской литературе для VI класса: «принцип построения курса - жанрово-хронологический: от былины и летописи до современной повести и лирической поэзии. Учащиеся получают представление о жанрах художественной литературы и фольклора, обучаются элементам сравнительного анализа» [3, с. 2]. На уроках ученики на примере «Повести временных лет» впервые знакомятся с таким жанром древнерусской литературы, как летопись. Летопись представлена учащимся как исторический и литературный памятник. $\mathrm{C}$ точки зрения литературных примеров ученикам предлагается познакомиться с стихотворением А. С. Пушкина «Песнь о вещем Олеге».

На взгляд авторов учебной программы русской литературы для VII класса также «принцип построения курса - жанрово-хронологический: учащиеся последовательно знакомятся с народными и литературными песнями, балладой В. А. Жуковского, повестью А. С. Пушкина, поэмой М. Ю. Лермонтова, комедией Н. В. Гоголя, рассказами Л. Н. Толстого и К. Г. Паустовского и другими произведениями» $[4$, с. 3$]$. Считается, что это позволит сформировать начальные представления о связи русской литературы с историческими событиями. В этой связи школьникам предлагается ознакомиться с народными и литературными историческими песнями: «Сон Степана Разина» («Ой, то не вечер, то не вечер...»), литературной исторической песней К. Ф. Рылеева «Смерть Ермака». Значительное внимание отводится на изучение исторической повести А. С. Пушкина «Капитанская дочка». В частности, при обсуждении этого произведения ученик должен ответить на вопрос учителя: «В чем историческая правда и художественный вымысел в повести?». При изучении литературы XX в. предлагается изучить творчество А. Т. Твардовского «Переправа», «Гармонь», «Два солдата», высказаться о истории создания поэмы, патриотическом пафосе «книги про бойца», объяснить ее популярность во время Великой Отечественной войны. 
Содержание курса русской литературы в VIII классе, в соответствии с положениями учебной программы, «строится по хронологическому принципу - от античной литературы до нашего времени. Учащиеся получают начальное представление об особенностях античной литературы, литературы эпохи Возрождения, русской классической литературы XIX века, литературы XX века» [5, с. 2]. Знакомство на уроках с произведениями русских авторов проходит не сразу, лишь на шестом уроке в рамках темы «Литература первой половины XIX в.», в ходе которого рассматриваются исторические события в Европе конца XVIII - начала XIX в., в том числе политическое и экономическое состояние России накануне войны 1812 г., подвиг народа в ней; ситуация в стране после войны. Ученикам предлагаются такие творения А. С. Пушкина, как «К морю», «Узник», «Сожженное письмо» и «Цыгане». Далее школьники изучают литературу второй половины XIX в. (Н. А. Некрасов «Плач детей», «Внимая ужасам войны...», И. С. Тургенев «Мы еще повоюем», «Русский язык», «Воробей», А. П. Чехов «Переполох»), литературу первой половины XX в. (В. В. Маяковский «Необычайное приключение, бывшее с Владимиром Маяковским летом на даче», «Хорошее отношение к лошадям»). Особо выделяется тема русской литературы в годы Великой Отечественной войны (А. А. Ахматова «Мужество», «Клятва»; К. М. Симонов «Жди меня...»; М. В. Исаковский «Враги сожгли родную хату...»; С. С. Орлов «Его зарыли в шар земной...»). Не была обойдена вниманием и роль в формировании общественного сознания поэзии и прозы 1950-1990-х гг. как литературы второй половины XX в. (Р. И. Рождественский «За того парня», «Все начинается с любви...», Е. А. Евтушенко «Людей неинтересных в мире нет...», «Я не сдаюсь, но все-таки сдаю...», Н. М. Рубцов «Русский огонек», «Утро»).

Считается, что учебная программа IX класса «отражает относительно завершенное образование по русской литературе, включая историколитературный процесс XI-XX вв., выстроенный на ключевых проблемах и творчестве писателей, дающих в художественном отражении объективное представление о мире и человеке» [6, с. 2]. Учащиеся после изучения этого предмета должны иметь прочные знания о истоках славянской письменности, основных этапах древнерусской литературы как колыбели русской, украинской и белорусской национальных литератур (XIXVII вв.). Школьники изучают «Слово о полку Игореве» как историко-культурный памятник славянских народов. В рамках рассмотрения русской литературы XVII в. анализируют как литературное произведение «Домострой».
По теме «Литература XVIII в.» школьники проходят произведения М. В. Ломоносова («Ода на день восшествия на Всероссийский престол Ея Величества Государыни императрицы Елисаветы Петровны 1747 года», «Разговор с Анакреоном»), Г. Р. Державина («Властителям и судиям», «Памятник», «Ласточка», «Снигирь»). Литература XIX в. в основном представлена произведениями романтизма: Е. А. Баратынский, К. Н. Батюшков, К. Ф. Рылеев, В. К. Кюхельбекер, А. А. Дельвиг. Особое внимание уделено В.А. Жуковскому («Вечер», «Море», «Сельское кладбище», «Светлана»). В рамках изучения русской литературы $\mathrm{XX}$ в. анализируется модернизм и реализм. Развитие литературы советского периода рассматривается в контексте истории России - литература СССР и русского зарубежья; перестройка и литература; роль возвращенной литературы. Как всегда, большое внимание уделено теме Великой Отечественной войны. Например, роман Б. Л. Васильева «А зори здесь тихие...».

В X классе учебная программа ориентирует учащихся на «освоение творчества писателейреалистов ... предполагается обращение к "золотому" фонду русской классической литературы второй половины XIX в., поскольку этот этап ее истории отмечен выдающимися достижениями, пользующимися всемирным признанием» [7, с. 3]. Нужно подчеркнуть, что учебный материал в этом классе подается в своеобразной историко-литературной форме. Учащиеся познают русскую литературу в контексте развития российской истории и русской литературы XIX в. Соответственен и подбор литературных произведений: Н. В. Гоголь «Мертвые души», А. Н. Островский «Гроза», «Бесприданница», Ф. И. Тютчев «Не то, что мните вы, природа...», «Природа сфинкс. И тем она верней...», «Silentium!», «Умом Россию не понять...», «О, как убийственно мы любим...», «К. Б.» («Я встретил вас и все былое...»), И. С. Тургенев «Отцы и дети», Н. А. Некрасов «Кому на Руси жить хорошо», Ф. М. Достоевский «Преступление и наказание», Л. Н. Толстой «Война и мир» и др.

Предметом изучения в выпускном XI классе становится русская литература XX в. Как отмечают авторы учебной программы: «важнейшая методологическая проблема курса литературы XI класса - традиции и новаторство в литературном процессе $\mathrm{XX}$ в., сосуществование различных художественных систем и творческая индивидуальность художника - рассматривается в социально-эстетическом аспекте взаимосвязей: писатель - общество - государство» [8, с. 1]. В этой связи рассматривается влияние на развитие литературы в России революций 1905 г., Февральской и Октябрьской 1917 г., Первой и Второй мировых войн, распада Советского Союза. 
Так, в теме «Модернизм конца XIX - начала XX в.» рассмотрены особенности русского модернизма. В теме «Литература 1920-х - середины 1950-х гг.» указывается на возникновение «двух потоков» русской литературы (литература метрополии и русского зарубежья). Отмечается, что главной темой литературы стала «Революция - Россия народ - личность». В теме «Литература 1940-х середины 1950-х гг.» рассматривается публицистика в годы Великой Отечественной войны (А. Н. Толстой, И. Г. Эренбург и др.), лирика (О. Ф. Берггольц, М. Джалиля), песенная поэзия (А. А. Сурков. «Бьется в тесной печурке огонь», «Соловьи»; А. И. Фатьянов и др.). Школьникам предлагаются эпические произведения, освещающие войну: А. А. Бек («Волоколамское шоссе»), А. А. Фадеев («Молодая гвардия»), В. С. Гроссман («Народ бессмертен»), К. М. Симонов («Дни и ночи»), Л. М. Леонов («Русский лес»). При изучении литературы середины 19501960-х гг. школьники должны увидеть попытки переосмысления исторического пути СССР с «позиций личности как главного критерия общественного прогресса» (П. Ф. Нилин «Жестокость», В. С. Гроссман «Жизнь и судьба», К. М. Симонов «Живые и мертвые», Ю. В. Бондарев «Горячий снег»). Взгляд на русскую литературу 1970-х начала 1990-х гг. должен дать школьнику понимание «системы "вечных" нравственных ценностей и исторической памяти народа» (В. Г. Распутин «Последний срок», «Живи и помни» и др.). Завершает учебный курс темой «Русская литература конца XX - начала XXI в.». Она демонстрирует развитие литературы в России в новых социокультурных условиях, отход от идеологических стандартов прошлых десятилетий, обращение к общечеловеческим проблемам (В. Г. Распутин «Женский разговор», «Новая профессия», «В ту же землю», «Изба», Е. И. Носов «Темная вода», «Алюминиевое солнце», В. И. Белов «Лейкоз», Т. Н. Толстая «Факир», «Легкие миры», О.А. Славникова «Стрекоза, увеличенная до размеров собаки», Д. И. Рубина «Уроки музыки», «Дорога домой», Б. П. Екимов «Учительница Маруся», «Елка для матери»).

В результате анализа данных учебных программ мы видим, что в средней школе Республики Беларусь уделяется большое внимание русской литературе. Имеется полноценный учебный предмет, в ходе изучения которого школьники на контекстном уровне повторяют и знакомятся с новыми аспектами российской истории.

Учитывая подобную значительную долю российской литературы и истории в белорусской школе, уместно задать вопрос: как обстоит ситуация с изучением белорусской литературы в школах России? Однако анализ аналогичных учебных программ позволяет сделать вывод об несоответствии и полном отсутствии ознакомления с литературными произведениями из Беларуси в школах России. Существование этой проблемы признают как белорусские, так и российские политики. Например, в 2017 г. на страницах центральной газеты Республики Беларусь «Беларусь сегодня» председатель Постоянной комиссии по образованию, культуре и науке Палаты представителей Национального собрания Беларуси И. А. Марзалюк отметил: «Культуру и литературу славян-соседей надо знать. А если мы говорим о Союзном государстве, то хорошо было бы, чтобы и в России изучали белорусскую литературу, пусть и в переводе на русский язык, как во времена Советского Союза» [9]. На двухсмысленность ситуации обратил внимание и специальный представитель президента Российской Федерации по международному культурному сотрудничеству М. Е. Швыдкой, бывший министр культуры России. На торжественном собрании «Союзное государство: открывая новые возможности», которое проходило в Минске 2 апреля 2021 г., он высказал следующее мнение: «Мы в школе читали Якуба Коласа наравне с Пушкиным, и это было нормой, чего, к сожалению, сейчас нет. Это, мне кажется, большой недостаток. Это одна из тем, над которой можно работать, когда мы говорим о Союзном государстве, - чтобы белорусская литература была представлена как часть школьной программы в России» [10].

Заключение. Таким образом, анализ учебных программ по «Русской литературе» в современной средней школе Республики Беларусь демонстрирует значительное внимание к наличию в учебных материалах сюжетов по истории России. В связи с этим можно констатировать тот факт, что уроки по русской литературе позволяют белорусским школьникам параллельно с познанием истории России непосредственно на уроках истории повторять и получать дополнительные сведения по истории этой страны и из курса «Русской литературы». Вместе с тем, на наш взгляд, процесс белорусско-российского взаимодействия в образовательной сфере в рамках союзного государства, существующего с 1999 г., да и в целом в области взаимопознания народов двух наших стран подразумевает обоюдный процесс и наличие в учебном плане средней школы Российской Федерации отдельной учебной дисциплины «Белорусская литература» либо включение в том же объеме учебных часов, как и в Республике Беларусь, в российские школьные учебные программы по литературе тем по белорусской литературе.

Статья выполнена при поддержке БРФФИ в рамках совместного белорусско-российского проекта «Историческая культура белорусов и россиян: формирование представлений о национальном и общем прошлом». 


\section{Список литературы}

1. Учебная программа по учебному предмету «Русская литература» для $\mathrm{V}$ класса учреждений общего среднего образования с белорусским и русским языками обучения и воспитания [Электронный ресурс]: утв. постановлением Министерства образования Республики Беларусь, 29.07.2019, № 123 // Национальный образовательный портал. URL: https://adu.by/ru/homepage/obrazovatelnyj-protsess2020-2021-uchebnyj-god/obshchee-srednee-obrazovanie-2020-2021/304-uchebnye-predmety-v-xi-klassy2020-2021/3804-russkaya-literatura.html (дата обращения: 01.09.2021).

2. Русская литература: учеб. пособие для 5 класса учреждений общего среднего образования с белорусским и русским языками обучения: в 2 ч. Ч. 2 / под ред. А. И. Гараниной. Минск: Национальный институт образования, 2019. 143 с.

3. Учебная программа по учебному предмету «Русская литература» для VI класса учреждений общего среднего образования с белорусским и русским языками обучения и воспитания [Электронный ресурс]: утв. постановлением Министерства образования Республики Беларусь, 29.07.2019, № 123 // Национальный образовательный портал. URL: https://adu.by/ru/homepage/obrazovatelnyj-protsess-20202021-uchebnyj-god/obshchee-srednee-obrazovanie-2020-2021/304-uchebnye-predmety-v-xi-klassy-20202021/3804-russkaya-literatura.html (дата обращения: 01.09.2021).

4. Учебная программа по учебному предмету «Русская литература» для VII класса учреждений общего среднего образования с белорусским и русским языками обучения и воспитания [Электронный pесурс]: утв. постановлением Министерства образования Республики Беларусь, 27.07.2019, № 91 // Национальный образовательный портал. URL: https://adu.by/ru/homepage/obrazovatelnyj-protsess2020-2021-uchebnyj-god/obshchee-srednee-obrazovanie-2020-2021/304-uchebnye-predmety-v-xi-klassy2020-2021/3804-russkaya-literatura.html (дата обращения: 01.09.2021).

5. Учебная программа по учебному предмету «Русская литература» для VIII класса учреждений общего среднего образования с белорусским и русским языками обучения и воспитания [Электронный ресурс]: утв. постановлением Министерства образования Республики Беларусь, 27.07.2018, № 76 // Национальный образовательный портал. URL: https:/adu.by/ru/homepage/obrazovatelnyj-protsess-20202021-uchebnyj-god/obshchee-srednee-obrazovanie-2020-2021/304-uchebnye-predmety-v-xi-klassy-20202021/3804-russkaya-literatura.html (дата обращения: 01.09.2021).

6. Учебная программа по учебному предмету «Русская литература» для IX класса учреждений общего среднего образования с белорусским и русским языками обучения и воспитания [Электронный ресурс]: утв. постановлением Министерства образования Республики Беларусь, 29.07.2019, № 123 // Национальный образовательный портал. URL: https://adu.by/ru/homepage/obrazovatelnyj-protsess-20202021-uchebnyj-god/obshchee-srednee-obrazovanie-2020-2021/304-uchebnye-predmety-v-xi-klassy-20202021/3804-russkaya-literatura.html (дата обращения: 01.09.2021).

7. Учебная программа по учебному предмету «Русская литература» для X класса учреждений общего среднего образования с белорусским и русским языками обучения и воспитания [Электронный ресурс]: утв. постановлением Министерства образования Республики Беларусь, 19.06.2020, № 140 // Национальный образовательный портал. URL: https://adu.by/ru/homepage/obrazovatelnyj-protsess-20202021-uchebnyj-god/obshchee-srednee-obrazovanie-2020-2021/304-uchebnye-predmety-v-xi-klassy-20202021/3804-russkaya-literatura.html (дата обращения: 01.09.2021).

8. Учебная программа по учебному предмету «Русская литература» для XI класса учреждений общего среднего образования с белорусским и русским языками обучения и воспитания [Электронный ресурс]: утв. постановлением Министерства образования Республики Беларусь, 27.07.2017, № 93 // Национальный образовательный портал. URL: https://adu.by/ru/homepage/obrazovatelnyj-protsess-20202021-uchebnyj-god/obshchee-srednee-obrazovanie-2020-2021/304-uchebnye-predmety-v-xi-klassy-20202021/3804-russkaya-literatura.html (дата обращения: 01.09.2021).

9. «СОЮЗ» сравнил школьные программы по литературе в Беларуси и России // Беларусь Сегодня, 26 января 2017 г. URL: https://www.sb.by/articles/chto-chitayut-nashi-deti.html (дата обращения: 15.06.2021).

10. Швыдкой: в российских школах нужно изучать творчество Коласа и других белорусских классиков // БЕЛТА - Новости Беларуси: информационный портал. URL: https://www.belta.by/society/ view/shvydkoj-v-rossijskih-shkolah-nuzhno-izuchat-tvorchestvo-kolasa-i-drugih-belorusskih-klassikov-4354942021/ (дата обращения: 20.06.2021).

\section{References}

1. Uchebnaya programma po uchebnomu predmetu "Russkaya literatura" dlya V klassa uchrezhdeniy obshchego srednego obrazovaniya s belorusskim i russkim yazykami obucheniya i vospitaniya [Curriculum on the academic subject "Russian literature" for the V grade of general secondary education institutions with the Belarusian and Russian languages of teaching and upbringing]. Available at: https://adu.by/ru/homepage/ 
obrazovatelnyj-protsess-2020-2021-uchebnyj-god/obshchee-srednee-obrazovanie-2020-2021/304-uchebnyepredmety-v-xi-klassy-2020-2021/3804-russkaya-literatura.html (accessed 01.09.2021).

2. Russkaya literatura: ucheb. posobie dlya 5 klassa uchrezhdeniy obshchego srednego obrazovaniya $s$ belorusskim i russkim yazykami obucheniya: v 2 ch. Ch. 2 [Russian literature: studies manual for the 5th grade of general secondary education institutions with Belarusian and Russian languages of instruction : in 2 books. Book 2]. Minsk, Natsional'nyy institut obrazovaniya Publ., 2019. 143 p.

3. Uchebnaya programma po uchebnomu predmetu "Russkaya literatura" dlya VI klassa uchrezhdeniy obshchego srednego obrazovaniya s belorusskim i russkim yazykami obucheniya i vospitaniya [Curriculum on the academic subject "Russian literature" for the VI grade of general secondary education institutions with the Belarusian and Russian languages of teaching and upbringing]. Available at: https://adu.by/ru/ homepage/obrazovatelnyj-protsess-2020-2021-uchebnyj-god/obshchee-srednee-obrazovanie-2020-2021/304uchebnye-predmety-v-xi-klassy-2020-2021/3804-russkaya-literatura.html (accessed 01.09.2021).

4. Uchebnaya programma po uchebnomu predmetu "Russkaya literatura" dlya VII klassa uchrezhdeniy obshchego srednego obrazovaniya s belorusskim i russkim yazykami obucheniya i vospitaniya [Curriculum on the academic subject "Russian literature" for the VII grade of general secondary education institutions with the Belarusian and Russian languages of teaching and upbringing]. Available at: https://adu.by/ru/homepage/ obrazovatelnyj-protsess-2020-2021-uchebnyj-god/obshchee-srednee-obrazovanie-2020-2021/304-uchebnyepredmety-v-xi-klassy-2020-2021/3804-russkaya-literatura.html (accessed 01.09.2021).

5. Uchebnaya programma po uchebnomu predmetu "Russkaya literatura" dlya VIII klassa uchrezhdeniy obshchego srednego obrazovaniya s belorusskim i russkim yazykami obucheniya i vospitaniya [Curriculum on the academic subject "Russian literature" for the VIII grade of general secondary education institutions with the Belarusian and Russian languages of teaching and upbringing]. Available at: https://adu.by/ru/ homepage/obrazovatelnyj-protsess-2020-2021-uchebnyj-god/obshchee-srednee-obrazovanie-2020-2021/304uchebnye-predmety-v-xi-klassy-2020-2021/3804-russkaya-literatura.html (accessed 01.09.2021).

6. Uchebnaya programma po uchebnomu predmetu "Russkaya literatura" dlya IX klassa uchrezhdeniy obshchego srednego obrazovaniya s belorusskim i russkim yazykami obucheniya i vospitaniya [Curriculum on the academic subject "Russian literature" for the IX grade of general secondary education institutions with the Belarusian and Russian languages of teaching and upbringing]. Available at: https://adu.by/ru/ homepage/obrazovatelnyj-protsess-2020-2021-uchebnyj-god/obshchee-srednee-obrazovanie-2020-2021/304uchebnye-predmety-v-xi-klassy-2020-2021/3804-russkaya-literatura.html (accessed 01.09.2021).

7. Uchebnaya programma po uchebnomu predmetu "Russkaya literatura" dlya X klassa uchrezhdeniy obshchego srednego obrazovaniya s belorusskim i russkim yazykami obucheniya i vospitaniya [Curriculum on the academic subject "Russian literature" for the X grade of general secondary education institutions with the Belarusian and Russian languages of teaching and upbringing]. Available at: https://adu.by/ru/homepage/ obrazovatelnyj-protsess-2020-2021-uchebnyj-god/obshchee-srednee-obrazovanie-2020-2021/304-uchebnyepredmety-v-xi-klassy-2020-2021/3804-russkaya-literatura.html (accessed 01.09.2021).

8. Uchebnaya programma po uchebnomu predmetu "Russkaya literatura" dlya XI klassa uchrezhdeniy obshchego srednego obrazovaniya s belorusskim i russkim yazykami obucheniya i vospitaniya [Curriculum on the academic subject "Russian literature" for the XI grade of general secondary education institutions with the Belarusian and Russian languages of teaching and upbringing]. Available at: https://adu.by/ru/ homepage/obrazovatelnyj-protsess-2020-2021-uchebnyj-god/obshchee-srednee-obrazovanie-2020-2021/304uchebnye-predmety-v-xi-klassy-2020-2021/3804-russkaya-literatura.html (accessed 01.09.2021).

9. SOYUZ compared school literature programs in Belarus and Russia. Belarus' Segodnya, 2017, 26 yanvarya [Belarus Today, January 26, 2017]. Available at: https://www.belta.by/society/view/shvydkoj-v-rossijskihshkolah-nuzhno-izuchat-tvorchestvo-kolasa-i-drugih-belorusskih-klassikov-435494-2021/ (accessed 15.06.2021).

10. Shvydkoy: v rossiyskikh shkolakh nuzhno izuchat' tvorchestvo Kolasa i drugikh belorusskikh klassikov [Shvydkoi: it is necessary to study the works of Kolas and other Belarusian classics]. Available at: https:/www.belta.by/society/view/shvydkoj-v-rossijskih-shkolah-nuzhno-izuchat-tvorchestvo-kolasa-i-drugihbelorusskih-klassikov-435494-2021/ (accessed 20.06.2021).

\section{Информация об авторе}

Острога Виктор Александрович - доктор исторических наук, профессор, заведующий кафедрой таможенного дела. Белорусский государственный университет $(220030$, г. Минск, пр. Независимости, 4, Республика Беларусь). E-mail: ostroga.v@mail.ru

\section{Information about the author}

Astroha Victor Alexandrovich - DSc (History), Professor, Head of the Department of Customs Affairs. Belarusian State University (4, Nezavisimosti Ave., 220030, Minsk, Republic of Belarus). E-mail: ostroga.v@mail.ru Поступила 10.09.2021 